\title{
STUDIES OF TOTAL PULMONARY CAPACITY AND ITS SUB- DIVISIONS. VI. OBSERVATIONS ON CASES OF OBSTRUCTIVE PULMONARY EMPHYSEMA ${ }^{1}$
}

\author{
BY ALBERTO HURTADO, NOLAN L. KALTREIDER, WALTER W. FRAY, \\ WILLIAM D. W. BROOKS ${ }^{2}$ AND WILLIAM S. MCCANN \\ (From the Department of Medicine of the School of Medicine and Dentistry of the \\ University of Rochester and the Medical Clinic and Division of Radiology \\ of the Strong Memorial Hospital and Rochester Municipal \\ Hospitals, Rochester, New York)
}

(Received for publication August 6, 1934)

The clinical conception of emphysema of the lungs appears to be poorly defined. Several types of the disorder may be recognized. It has become highly important to differentiate clearly these types, to decide whether they are due chiefly to anatomical or functional derangements. An equally important consideration is the quantitative estimation of the degree of respiratory disability; a problem which is encountered in all cases of chronic pulmonary disease. In spite of the numerous observations on the etiological factors and functional pathology in diseases of the respiratory system a review of the literature fails to disclose a serious or sustained effort in correlating the abnormalities observed and the degree of the respiratory insufficiency.

Studies of the total pulmonary capacity and its subdivisions in normal subjects and in patients with chronic respiratory disease, mainly pulmonary fibrosis and emphysema, were begun a few years ago in this clinic to learn whether the failure of respiratory adjustment to increased demand for ventilation in these cases is related proportionally to alterations in the pulmonary capacity. The observations on the cases of pulmonary emphysema are presented in this communication.

\section{METHODS}

The terminology and the methods employed for the determination of total pulmonary capacity and its subdivisions, as well as the findings in

1 The expenses of the investigation were defrayed from a fund contributed by the Corning Glass Company, The Eastman Kodak Company, The American Grinding Wheel Manufacturing Association, The American Laundry Machinery Company, The Gleason Works, The Symington Company and the Pfaudler Company.

${ }^{2}$ Travelling Fellow of the Rockefeller Foundation; Ferëday Fellow, St. John's College, Oxford. 
normal subjects, have been fully presented in previous papers (1), (2). For convenience we may briefly summarize the usual procedures. After a previous rest and with the subject in the recumbent position the residual air was determined by the oxygen dilution method of Christie (3); the vital capacity, reserve and complementary air were graphically recorded. Two observations were made in each case. The external chest measurements were taken, and immediately afterwards with the subject in the same recumbent position a doubly exposed roentgenogram of the chest was obtained at the respiratory positions of forced expiration and inspiration. Measurements were made on this film to determine the degree of chest expansion, and by means of a planimeter the areas of the lung fields at maximum expiration and inspiration. The latter area multiplied by the anteroposterior diameter of the chest in the same respiratory position gave the so-called " radiological chest volume," from which the corresponding normal pulmonary capacity was predicted in each case by means of a regression formula. In each case the observed volumes were compared with the predicted values.

It was anticipated that difficulty would be encountered in establishing a complete admixture between the oxygen-air mixture in the spirometer and the large volume of residual air in the lungs during the rebreathing period in cases of pronounced emphysema. However, we have found that this is not the case. Repeated determinations of the residual air on the same patients have agreed closely, not only during the same day, but also in later observations, and it is quite unlikely that the same degree of imperfect mixing would occur each time. We have concluded that the oxygen dilution method of Christie is applicable to the study of cases of this nature, but as in previous studies (4) we have found it to be more convenient to determine directly the residual air rather than the mid capacity (called "functional residual air" by Christie). It is important that the time of rebreathing be kept constant in all cases, because prolongation of this time may lead to a rise in the nitrogen percentage in the spirometerlung system due to the continuous excretion of nitrogen from the circulating blood into the alveoli, thus giving an error in the value for the residual volume. Failure to appreciate and correct for this error might lead one to the conclusion that imperfect mixing had occurred. In each of our cases we have employed a rebreathing period of seven minutes.

A summary of the important clinical findings in each case is given in an appendix at the end of this paper. A total of twenty-six cases has been studied, of which twenty-four were males and two females. The ages varied between 17 and 64 years with an average of 45 years; with the exception of two individuals, all were above 20 years of age. Most of the patients had bronchitic asthma, and had signs of emphysema or the complaint of constant shortness of breath. It is obvious that the present study has no statistical relation to the incidence of pulmonary emphysema 
in patients with chronic asthma, as the cases were selected on the above basis.

In all cases a complete history and physical examination were recorded, including roentgenographic studies of the chest. In most cases an electrocardiogram was made. The usual complaints were dyspnea and cough, the duration of which varied between one and forty years. Dyspnea was present in all cases. The patient's statement and the physical examination were carefully analyzed in an attempt to estimate the degree of dyspnea, which varied from a sensation of discomfort of which the patient was barely conscious during severe physical activity to marked shortness of breath occurring even at rest. A history of asthmatic attacks at frequent or infrequent intervals was given in all but three instances (Cases 1, 4. and 26), and chronic bronchitis with periods of exacerbations was a complaint common to all the patients. In no case was the determination of the pulmonary capacity or the roentgenological examination of the chest made during the acute respiratory distress of an asthmatic attack.

There was a wide range in the type of chest observed in these patients ranging from the typical barrel shaped emphysematous thorax to those in which the chest appeared of normal size and contour. Chest examination revealed in most cases an increased anteroposterior diameter, limited expansion, low position of the diaphragm, hyperresonance, prolongation of the expiration and scattered râles chiefly of the musical variety. In five cases clubbing of the fingers was present and in eight patients cyanosis of the lips and other mucous membranes was pronounced. The roentgenographic appearance of the lungs varied markedly. Among the most constant and prominent findings were increased linear markings, accentuation of the hilar shadows, increased radiability of the lung fields, flaring of the ribs with a widening of the intercostal spaces; in a few cases there was evidence of pleural thickening, and more infrequently of pleural adhesions about the diaphragm (see Figure 1). In one case the roentgenogram showed an enlargement of the left ventricle and in another a prominent pulmonary conus.

In sixteen cases electrocardiograms were taken. Five of them were interpreted as normal, and in six cases there was evidence of left ventricular preponderance. Myocardial damage was suspected in four cases and sino-auricular tachycardia was observed in two others. One patient showed an intraventricular conduction defect. In no case was there evidence of right ventricular preponderance. None of the cases had peripheral edema or revealed other signs of congestive heart failure. Although the symptoms of marked emphysema and those of cardiac decompensation are somewhat similar, we concluded after a careful consideration of the clinical, radiological and electrocardiographic studies that the cardiac factor played no prominent part in these cases. 


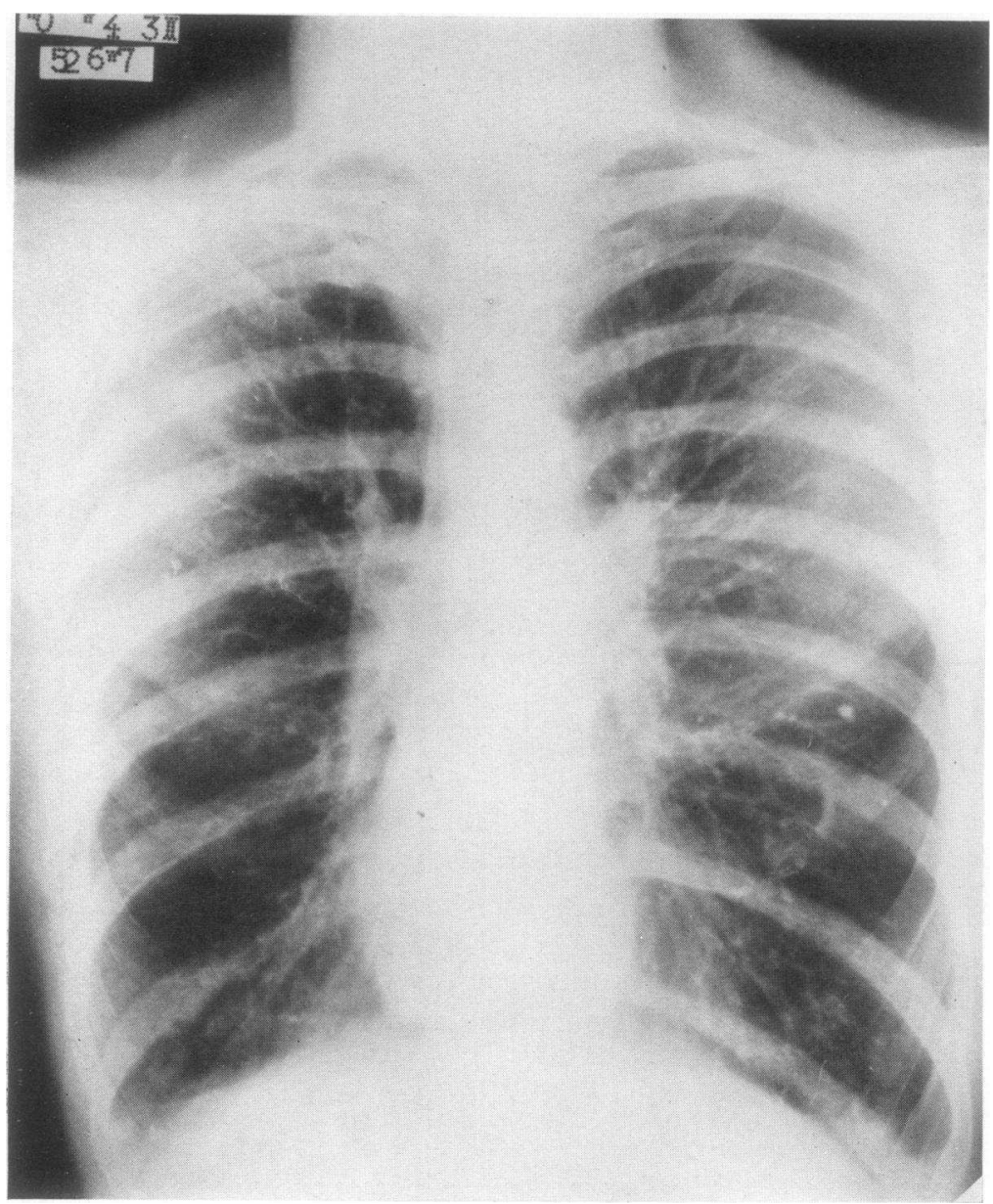

Fig. 1. Typical. Ronntgenographic Appearance of the Llengs in Pllmonary Emphysema (Case 17 )

In Case 1 an autopsy revealed changes in the lungs characteristic of marked emphysema. Grossly they were very voluminous and beneath the pleural surface several large dilated alveoli were noted, the largest measuring $5 \mathrm{~mm}$. The cut surface was also emphysematous. A few yellow raised plaques were visible on the intimal surface of the pulmonary vessels. Microscopically, the bronchiolar epithelium was everywhere hyperplastic and the bronchioles in general were slightly dilated. The epithelium lining some of the markedly dilated alveoli was cuboidal. The connective tissue stroma, especially about the bronchioles was greatly increased. It was in the portion of this connective tissue adjacent to the alveoli as well as in the bronchial walls that cellular infiltration was most 
marked. Both sides of the heart were somewhat hypertrophied and dilated, most markedly on the right. There was some calcification of the aortic valves. These marked abnormalities of the lungs correlate well with the clinical condition of the patient, the extreme respiratory disability and the marked alterations which were found in the various components of the pulmonary capacity.

The venous blood pressure (indirect method of Eyster (5)) was determined in six cases. The readings varied between 50 and $120 \mathrm{~mm}$. of water, with an average value of 73 , which is in the upper zone of normal range. All of the values except one were above $70 \mathrm{~mm}$. of water. These results are similar to those found by Kountz, Pearson and Koenig (20) in 5 cases of pulmonary emphysema.

Other measurements included blood volume, oxygen saturation of the arterial blood, etc. These observations will be presented in other communications and it.is sufficient to state here that no significant abnormality was found in the erythrocytes or in the volume of the blood, but a definite decrease in the oxygen saturation of the arterial blood was frequently observed.

\section{Determinations of pulmonary capacity}

We have summarized in Table I the observed values for the total pulmonary capacity and its main subdivisions as compared with the corresponding normal values predicted on the basis of the "radiological chest volume." Such comparison may be better appreciated in Figure 2. In the group of patients with emphysema the mean observed value for the vital capacity was 2.88 liters or a decrease of 38.8 per cent of the calculated value, with variations between 1.44 and 4.18 liters. The residual air was greatly increased; the average value was 2.84 liters or an increase of 110.3 per cent over that of the normal, with marked fluctuations between 1.39 and 5.82 liters, while the observed value for the total capacity showed a decrease of only 5.7 per cent of the normal value. It is evident that there was a wide range of variation in these observed volumes, ranging from rather moderate to marked deviations from the predicted capacities. But a close analysis reveals that there were certain constant findings in all cases chiefly characterized by a definite decrease in the vital capacity with a corresponding increase in the residual air, so that the total capacity as a rule approximated the normal value. Of the two components of the vital capacity the complementary air seemed to be the one most affected by the reduction. The mid capacity was also increased in all cases.

We must call attention to the fact that the normal values used for comparison in this series are based on observations in younger adults, and it is likely that the observed deviations from normality would not have been so great if normal subjects of similar ages had been used for comparison. That the vital capacity decreases with age is a well known fact, 


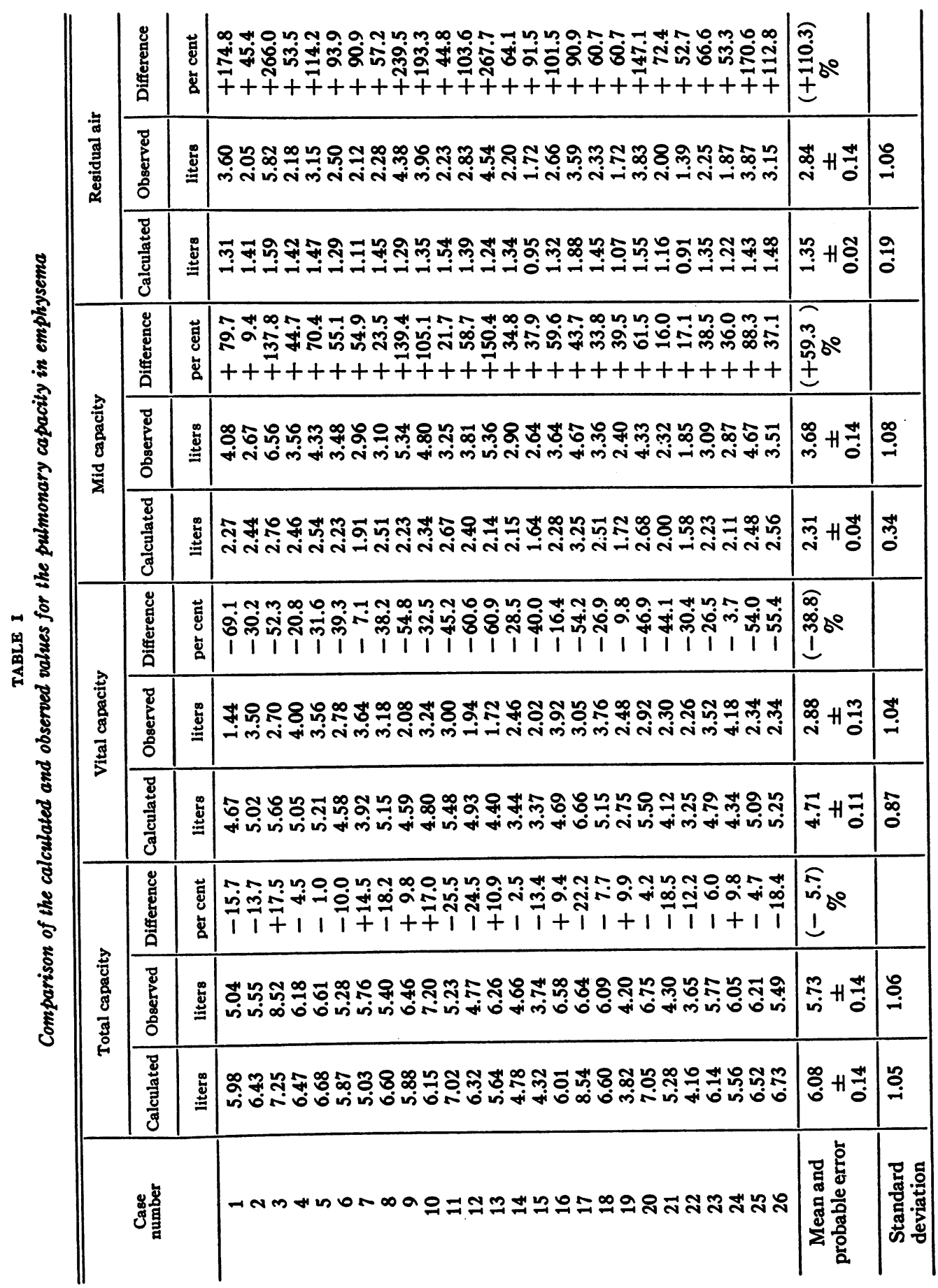




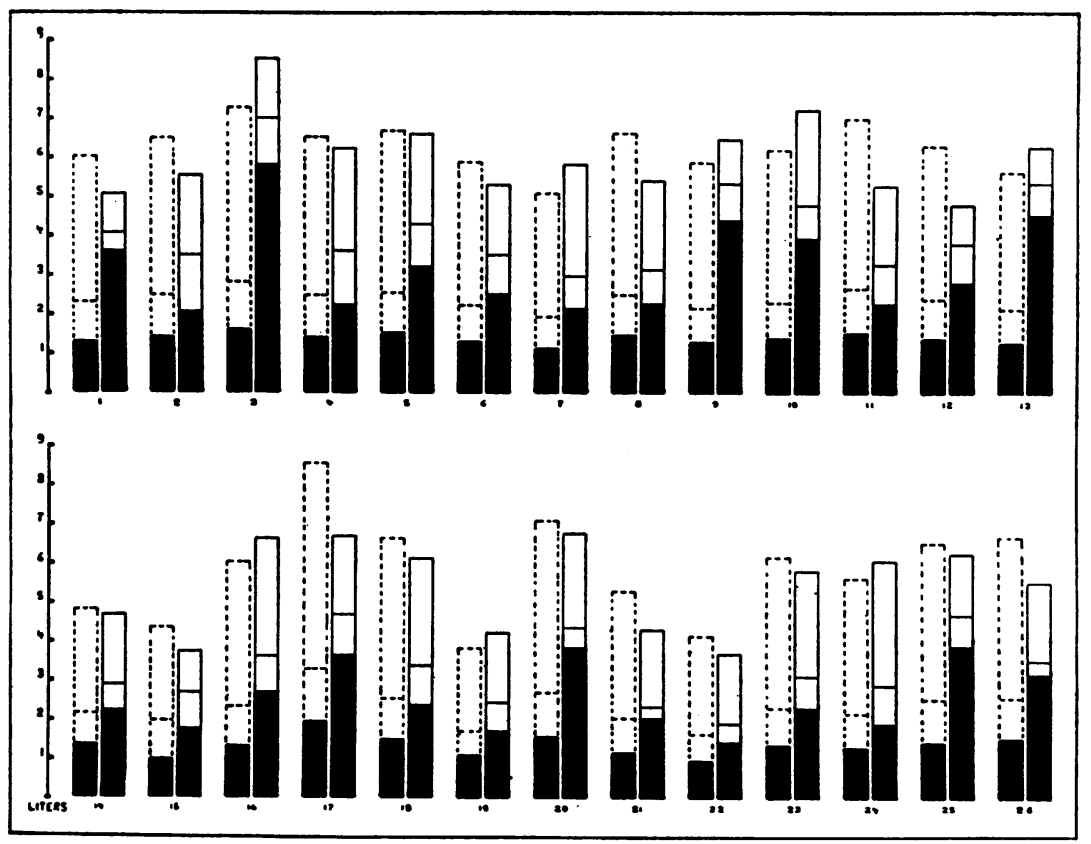

Fig. 2. Calculated and Observed Pulmonary Capacity in Emphysema

Each case is represented by two columns: on the left with broken lines the calculated value is given; on the right is the observed pulmonary capacity. The black area represents the residual air; the white space above is the vital capacity. The line dividing the vital capacity is the level of the mid capacity.

although according to several investigators (6) (7) (8) (9) a significant lowering is not evident until after 60 years of age. Whether this is accompanied by a corresponding increase in the residual air is not known and an investigation of this matter is now being made in this clinic. However, the changes are so constant and well marked that we do not believe that the general conclusions will be altered. It may be mentioned here that in the cases of the two female patients the normal values found for this sex (4) have been used for comparative purposes.

The observed relative values (total capacity $=100$ per cent) of the main subdivisions of the total pulmonary capacity are presented in Table II and graphically in Figure 3. One may readily see that there is a marked decrease in the relative value of the vital capacity with a corresponding increase in the residual air. The mid capacity is also increased. The significance of these findings in relation to the respiratory disability will be discussed later. Also the complementary air makes up a smaller percentage of the vital capacity (mean value 70.8 per cent) than in normal subjects (79.4 per cent). In some cases the reduction in the complementary 
TABLE II

Relative values for the subdivisions of pulmonary capacity in emphysema

\begin{tabular}{|c|c|c|c|c|}
\hline $\begin{array}{c}\text { Case } \\
\text { number }\end{array}$ & $\begin{array}{c}\text { Ratio } \\
\text { Vital capacity } \\
\frac{\text { Total capacity }}{\times 100}\end{array}$ & $\frac{\text { Ratio }}{\text { Mid capacity }}$ & $\frac{\stackrel{\text { Ratio }}{\text { Residual air }}}{\underset{\times 100}{\text { Total capacity }}}$ & $\frac{\begin{array}{c}\text { Ratio } \\
\text { Complementary air }\end{array}}{\begin{array}{c}\text { Vital capacity } \\
\times 100\end{array}}$ \\
\hline $\begin{array}{r}1 \\
2 \\
3 \\
4 \\
5 \\
6 \\
7 \\
8 \\
9 \\
10 \\
11 \\
12 \\
13 \\
14 \\
15 \\
16 \\
17 \\
18 \\
19 \\
20 \\
21 \\
22 \\
23 \\
24 \\
25 \\
26\end{array}$ & $\begin{array}{l}28.6 \\
63.1 \\
31.7 \\
64.7 \\
53.8 \\
52.7 \\
63.2 \\
57.8 \\
32.2 \\
45.0 \\
52.3 \\
40.7 \\
27.5 \\
52.8 \\
54.1 \\
59.6 \\
45.9 \\
61.8 \\
59.0 \\
43.3 \\
53.5 \\
61.9 \\
61.0 \\
69.0 \\
37.6 \\
42.7\end{array}$ & $\begin{array}{l}80.9 \\
48.1 \\
77.0 \\
57.6 \\
65.5 \\
65.9 \\
51.4 \\
57.4 \\
82.6 \\
66.6 \\
62.1 \\
79.8 \\
85.6 \\
62.2 \\
70.6 \\
55.3 \\
70.4 \\
48.1 \\
57.1 \\
64.1 \\
53.9 \\
50.7 \\
53.5 \\
47.4 \\
75.2 \\
63.9\end{array}$ & $\begin{array}{l}71.4 \\
36.9 \\
68.3 \\
35.3 \\
46.4 \\
47.3 \\
36.8 \\
42.2 \\
67.8 \\
55.0 \\
42.7 \\
59.3 \\
72.5 \\
47.2 \\
45.9 \\
40.4 \\
54.1 \\
38.2 \\
41.0 \\
56.7 \\
46.5 \\
38.1 \\
39.0 \\
31.0 \\
62.4 \\
57.3\end{array}$ & $\begin{array}{l}66.6 \\
82.3 \\
72.6 \\
65.5 \\
66.8 \\
64.7 \\
77.0 \\
74.2 \\
53.8 \\
74.1 \\
66.0 \\
49.4 \\
52.3 \\
75.6 \\
54.4 \\
75.0 \\
64.6 \\
84.0 \\
72.6 \\
82.8 \\
86.1 \\
79.6 \\
76.1 \\
76.0 \\
65.8 \\
84.6\end{array}$ \\
\hline $\begin{array}{c}\text { Mean and } \\
\text { probable error }\end{array}$ & $50.4 \pm 1.49$ & $64.0 \pm 1.52$ & $49.6 \pm 1.52$ & $70.8 \pm 1.37$ \\
\hline Standard deviation & 11.3 & 11.5 & 11.5 & 10.4 \\
\hline
\end{tabular}

air is so great, as compared with that of the reserve volume, that the vital capacity is made up almost equally of these two subdivisions (see Figure 4). Whether this abnormal composition of the vital capacity, that is the relative increase in the reserve air, has a rôle in itself in the respiratory difficulty of the emphysematous patient is an important point to be considered in future studies.

Previous investigations of the pulmonary capacity in cases of emphysema have yielded results identical with those obtained by us. Bruns (10), Bittorf and Forschbach (11) in 1910, Porges, Leimdörfer and Markovici (12), Plesch (13) in 1913, Lundsgaard and Schierbeck (14) in 1923, and more recently Anthony (15), Herms and Rüttgers (16), Hurtado, Fray and McCann (17) and Christie (18) have also reported a relative and absolute increase in the residual air with a proportional reduction of the 


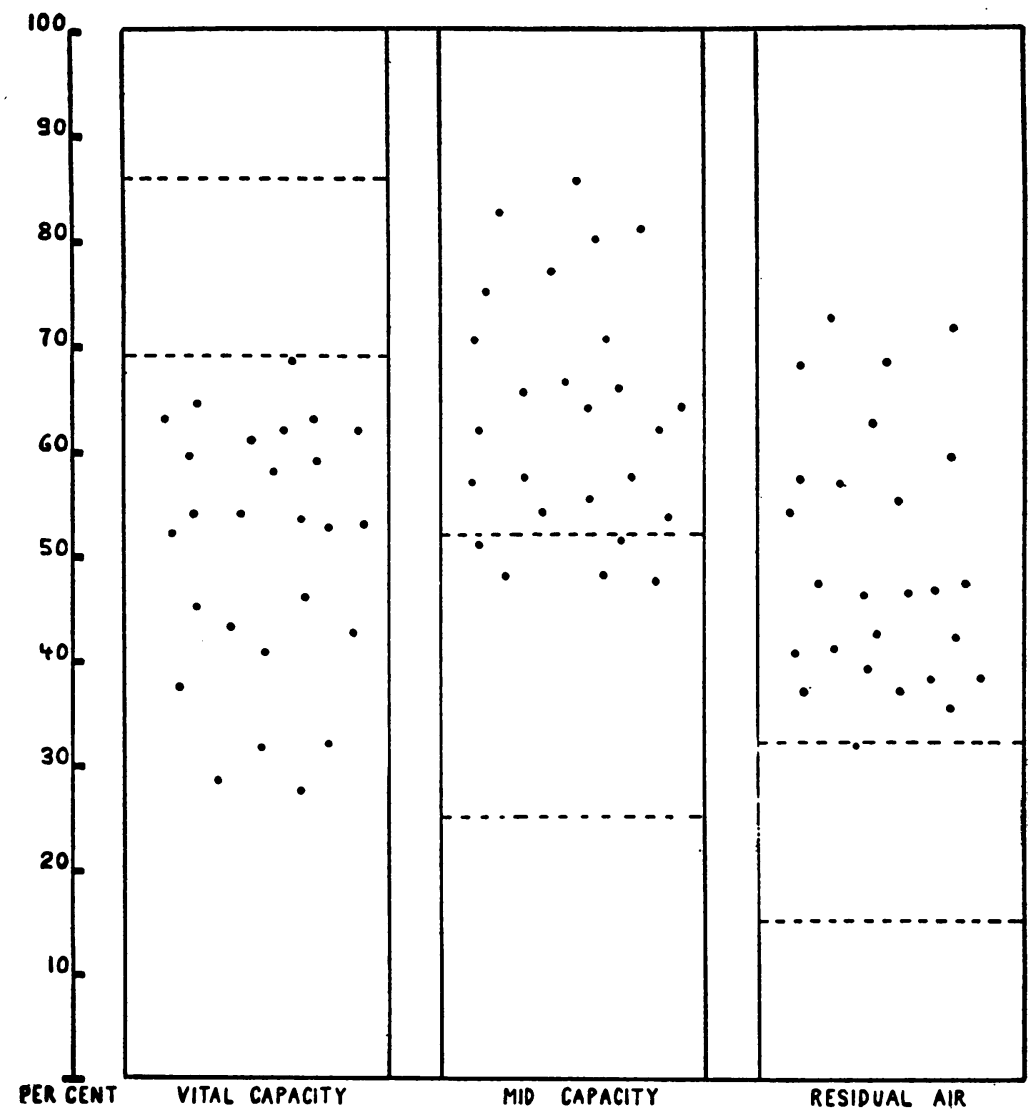

Fig. 3. Vital Capacity, Mid Capacity and Residual Air Expressed in Percentage of the Total Capacity

Dots represent individual observations. The areas between lines are the limits of normal variation.

vital capacity so that the total capacity is kept within normal limits. In a few cases the latter was found to be higher than the normal due to a great increase in the residual volume; Cases 3 and 10 in our series belong to this group.

Christie (18) in his study of seven cases of pulmonary emphysema calls attention to the fact that the reserve air is constantly decreased or even absent; an observation not entirely in agreement with our experience in this larger group of cases. Although the reduction in the reserve air has been frequently observed it has not usually been great, and even in cases of marked emphysema with a large increase in the residual air we have observed a nearly normal value of the reserve air, as compared with the considerable decrease in the complementary air. We have been unable to con- 


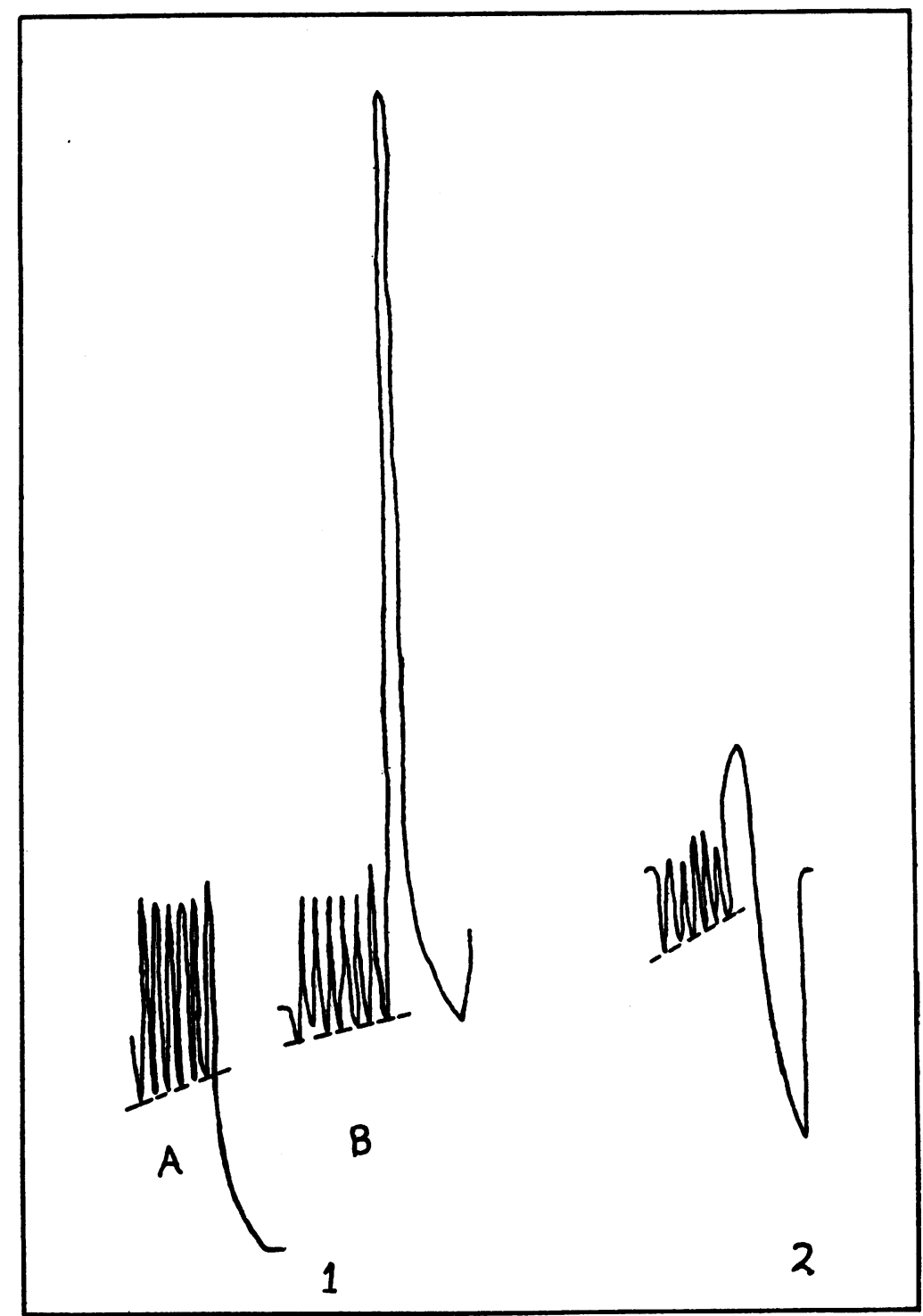

Fig. 4. Respiratory Tracings in Cases of Pulmonary Emphysema

1. $A$-the reserve volume after a tidal inspiration. $B$-the reserve volume in the same patient after a deep inspiration. Notice the decrease of this volume and the prolongation of the last part of the expiratory act, i.e. Christie's sign. 2. Relative increase of the reserve air as part of the vital capacity. 
firm the observation of Christie that the decrease or disappearance of the reserve air after a deep inspiration, as compared with that determined after a normal tidal inspiration, is a constant finding. He interprets this observation as important evidence of the loss of pulmonary elasticity. In Table III are the data of 22 cases studied from this point of view which show that this phenomenon was found in only nine instances (41 per cent).

TABLE III

Cases of emphysema in which the reserve air was decreased by $100 \mathrm{cc}$. or more after a forced inspiration *

\begin{tabular}{|c|c|c|c|c|c|c|c|c|}
\hline \multirow{2}{*}{$\begin{array}{c}\text { Case } \\
\text { number }\end{array}$} & \multirow{2}{*}{$\begin{array}{l}\text { Amount } \\
\text { of } \\
\text { reduc- } \\
\text { tion }\end{array}$} & \multicolumn{3}{|c|}{ Vital capacity } & \multicolumn{3}{|c|}{ Residual air } & \multirow{2}{*}{$\frac{\text { Ratio }}{\text { Residual air }}=100$} \\
\hline & & $\begin{array}{l}\text { Calcu- } \\
\text { lated }\end{array}$ & $\begin{array}{c}\text { Ob- } \\
\text { served }\end{array}$ & $\begin{array}{c}\text { Differ- } \\
\text { ence }\end{array}$ & $\begin{array}{l}\text { Calcu- } \\
\text { lated }\end{array}$ & $\begin{array}{c}\text { Ob- } \\
\text { served }\end{array}$ & $\begin{array}{c}\text { Differ- } \\
\text { ence }\end{array}$ & \\
\hline & liters & liters & liters & per cent & liters & liters & per cent & \\
\hline 2 & 0.40 & 5.02 & 3.50 & -30.2 & 1.41 & 2.05 & +45.4 & 36.9 \\
\hline 6 & 0.16 & 4.58 & 2.78 & -39.3 & 1.29 & 2.50 & $\begin{array}{r}+93.9\end{array}$ & 47.3 \\
\hline 8 & 0.12 & 5.15 & 3.18 & -38.2 & 1.45 & 2.28 & +57.2 & 42.2 \\
\hline 10 & 0.12 & 4.80 & 3.24 & -32.5 & 1.35 & 3.96 & +193.3 & 55.0 \\
\hline 14 & 0.14 & 3.44 & 2.46 & -28.5 & 1.34 & 2.20 & $\begin{array}{l}+64.1 \\
\end{array}$ & 47.2 \\
\hline 15 & 0.54 & 3.37 & 2.02 & -40.0 & 0.95 & 1.72 & +91.5 & 45.9 \\
\hline 16 & 0.40 & 4.69 & 3.92 & -16.4 & 1.32 & 2.66 & +101.5 & 40.4 \\
\hline 18 & 0.34 & 5.15 & 3.76 & -26.9 & 1.45 & 2.33 & +60.7 & 38.2 \\
\hline 24 & 0.16 & 4.34 & 4.18 & -3.7 & 1.22 & 1.87 & +53.3 & 31.0 \\
\hline
\end{tabular}

* Of 22 cases investigated only 9 (41 per cent) showed such a decrease.

These data also show no relationship between the decrease in the reserve air and the increase in the residual volume or the decrease in the vital capacity. We do not believe that the failure to find this abnormality is due to any lack of cooperation or training on the part of the subjects, as only those who were intelligent enough to be reliable were selected for this study. In each instance at least four determinations of reserve air were made after normal tidal breathing and three observations of the vital capacity were made. In Figure 4 is shown the respiratory tracing of a patient to which the decrease in the reserve air after a full inspiration was observed. It may also be noted that the curved end of the respiratory tracing is evidence of the difficulty in accomplishing the last part of the expiratory act.

It would be of interest to know whether or not there is a larger respiratory dead space in cases of pulmonary emphysema. An increase in dead space would present a further obstacle to efficient alveolar ventilation. We have investigated this matter in 12 cases, the results of which are presented in Table IV. The data show that the observed values of the dead space vary considerably, being influenced chiefly by the depth of the respiration. This fact has been previously observed in normal subjects (4). The dead 
TABLE IV

Respiratory dead space (calculated from the tidal volume and the $\mathrm{CO}_{2}$ and $\mathrm{O}_{2}$ percentage of the alveolar and expired air)

\begin{tabular}{c|c|c|c|c|c}
\hline \hline $\begin{array}{c}\text { Case } \\
\text { number }\end{array}$ & $\begin{array}{c}\text { Ventilation } \\
\text { per minute }\end{array}$ & $\begin{array}{c}\text { Respirations } \\
\text { per minute }\end{array}$ & $\begin{array}{c}\text { Tidal } \\
\text { volume }\end{array}$ & $\begin{array}{c}\text { Dead space } \\
\text { (from Co. } \\
\text { per cent) }\end{array}$ & $\begin{array}{c}\text { Dead space } \\
\text { (from Os } \\
\text { per cent) }\end{array}$ \\
\cline { 2 - 6 } 2 & liters & 18 & liters & $c c$. & $c c$. \\
5 & 6.75 & 0.35 & 132 & 122 \\
6 & 7.12 & 6 & 1.31 & 496 & 660 \\
9 & 8.86 & 18 & 0.48 & 216 & 221 \\
11 & 8.49 & 21 & 0.40 & 232 & 193 \\
14 & 6.89 & 18 & 0.38 & 197 & 221 \\
15 & 6.45 & 16 & 0.40 & 159 & 176 \\
16 & 5.40 & 23 & 0.24 & 47 & $17(?)$ \\
19 & 7.11 & 16 & 0.45 & 153 & 184 \\
20 & 7.23 & 15 & 0.47 & 182 & 181 \\
23 & 8.44 & 17 & 0.51 & 91 & 83 \\
25 & 9.18 & 19 & 0.48 & 166 & 148 \\
\hline Average & 7.04 & 16 & 0.44 & 204 & 229 \\
\hline
\end{tabular}

space of emphysematous subjects, when calculated on the basis of the tidal volume and the carbon dioxide and oxygen percentages of the alveolar and expired air, was found to average 189 and $203 \mathrm{cc}$. respectively in observations in which the average tidal volume was 0.49 liter. These values were slightly higher than those usually found in normal subjects (dead space of $150 \mathrm{cc}$. for a tidal volume of 0.50 liter). However, since all investigators agree that no true sample of mixed alveolar air from subjects with pulmonary emphysema is ever likely to be obtained by the usual procedure, some caution must be used in accepting these results. In view of the questionable character of the calculations employed above we have commenced to use a new procedure for the measurement of the dead space in the hope of achieving more reliable results. The method consists in taking several samples of air in rapid succession during the course of a single expiration. The total volume of the expiration is graphically recorded, and the time and volume which has passed at the instant of taking each sample is shown. In this way the curve of the gradient of $\mathrm{CO}_{2}$ in a single expiration may be plotted and used as a basis for calculation of the dead space. These investigations are being carried out at the present time. Two of the curves are presented in Figure 5, one obtained in a normal subject and another in a case of emphysema (Case 25). The point at which the carbon dioxide content of the expired air becomes constant is not appreciably different in the curves of these two subjects. Although no definite conclusion has been reached at the present time, it seems likely that the respiratory dead space in emphysema does not differ appreciably from that of the normal subject. 


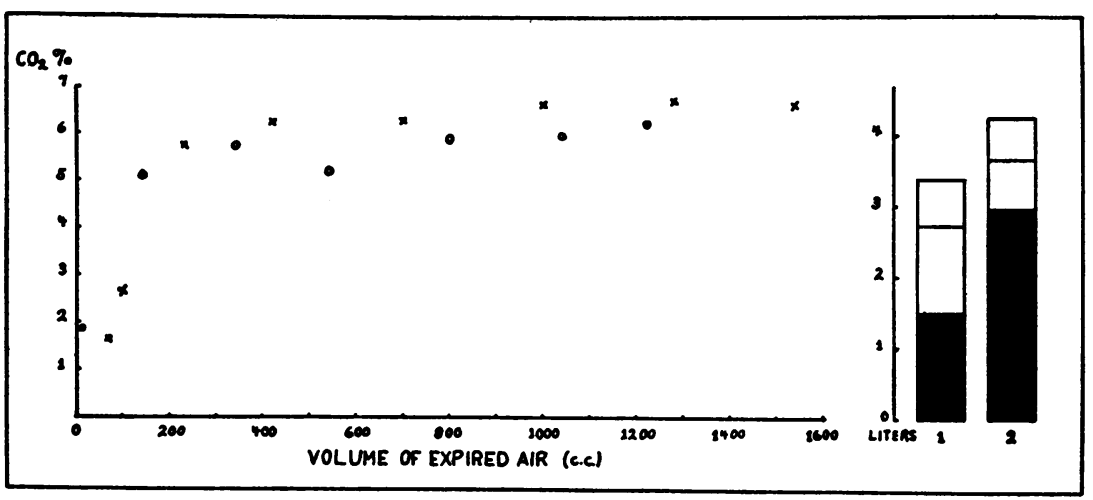

Fig. 5. $\mathrm{CO}_{2}$ Content of Several Samples of Air Taken at Known Volumes in a Single Expiration, in a Normal Male Subject (Crosses) and in a Case of Pulmonary Emphysema (Circles).

Columns on the right represent the total air content of the lungs at the moment the expiration was started: black area represents the residual air; the upper white area is the tidal volume and the lower white area is the reserve air.

Column 1 corresponds to the normal subject and column 2 to the case of emphysema.

\section{Chest expansion}

We have studied the expansion of the chest by means of a doubly exposed roentgenographic film taken at the respiratory positions of forced expiration and inspiration with the patient in the recumbent position. Measurements of the areas of the lung fields (by means of a planimeter) and of the excursion of the diaphragm and the lateral expansion of the chest, as well as the degree of rotation of the ribs gave a fairly good indication of the ability and extent to which the thorax may be expanded. Such measurements are summarized in Table V. The ratio,

$$
\frac{\text { Area at maximum expiration }}{\text { Area at maximum inspiration }} \times 100 \text {, }
$$

had a mean value of 73.4 per cent with extremes of 56.6 and 90.9 . This mean value was distinctly higher than the one obtained in the study of a group of normal subjects (62.2 with a standard deviation of 4.4 ). All cases, except two, showed a higher ratio than the mean normal value.

A more or less constant finding in this series of cases was a diminution of the diaphragmatic excursion and of the lateral expansion of the chest, the mean values of which were 4.0 and 2.4 centimeters respectively, as compared with the normal mean values of 6.3 and 3.2 centimeters. The degree of rib movement was also decreased in most cases and in some instances there was practically no rotation of the rib during the two phases of respiration. In spite of the wide variation in the measurements above mentioned it is evident that there is a definite diminution in the ability 
TABLE V

Chest expansion * in emphysema

\begin{tabular}{|c|c|c|c|c|c|c|}
\hline \multirow{2}{*}{$\begin{array}{c}\text { Case } \\
\text { number }\end{array}$} & \multirow{2}{*}{$\frac{\text { Area at maximum expiration }}{\text { Area at maximum inspiration }} \times 100$} & \multicolumn{3}{|c|}{ Diaphragmatic excursion } & \multirow{2}{*}{$\begin{array}{c}\text { Rib } \\
\text { movement }\end{array}$} & \multirow{2}{*}{$\begin{array}{c}\text { Lateral } \\
\text { expansion }\end{array}$} \\
\hline & & Right & Left & Average & & \\
\hline $\begin{array}{r}1 \\
2 \\
3 \\
4 \\
5 \\
6 \\
7 \\
8 \\
9 \\
10 \\
11 \\
12 \\
13 \\
14 \\
15 \\
16 \\
17 \\
18 \\
19 \\
20 \\
21 \\
22 \\
23 \\
24 \\
25 \\
26\end{array}$ & $\begin{array}{l}82.9 \\
74.7 \\
86.8 \\
70.7 \\
71.8 \\
73.4 \\
75.5 \\
71.8 \\
80.6 \\
82.6 \\
71.3 \\
85.7 \\
84.9 \\
66.3 \\
68.8 \\
69.0 \\
90.9 \\
64.8 \\
68.7 \\
67.3 \\
56.6 \\
68.5 \\
61.2 \\
59.1 \\
75.3 \\
85.9\end{array}$ & $\begin{array}{l}c m . \\
4.1 \\
1.0 \\
3.4 \\
4.8 \\
4.1 \\
3.6 \\
4.3 \\
5.2 \\
2.3 \\
1.7 \\
3.9 \\
1.9 \\
2.1 \\
2.9 \\
5.2 \\
3.3 \\
0.0 \\
6.0 \\
4.5 \\
5.4 \\
6.3 \\
2.0 \\
5.5 \\
5.5 \\
2.4 \\
0.5\end{array}$ & $\begin{array}{l}c m . \\
5.5 \\
4.1 \\
3.3 \\
5.5 \\
5.7 \\
4.9 \\
4.4 \\
5.4 \\
4.7 \\
1.1 \\
6.0 \\
3.9 \\
2.8 \\
4.9 \\
4.5 \\
4.3 \\
0.6 \\
6.0 \\
4.2 \\
4.8 \\
6.2 \\
2.3 \\
7.5 \\
5.5 \\
3.4 \\
2.2\end{array}$ & $\begin{array}{l}c m . \\
4.8 \\
2.6 \\
3.4 \\
5.1 \\
4.9 \\
4.3 \\
4.4 \\
5.3 \\
3.5 \\
1.4 \\
5.0 \\
2.9 \\
2.5 \\
3.9 \\
4.9 \\
3.8 \\
0.3 \\
6.0 \\
4.4 \\
5.1 \\
6.3 \\
2.2 \\
6.5 \\
5.5 \\
2.9 \\
1.4\end{array}$ & $\begin{array}{c}\text { degrees } \\
2 \\
17 \\
7 \\
11 \\
15 \\
18 \\
22 \\
9 \\
11 \\
18 \\
14 \\
9 \\
3 \\
22 \\
17 \\
24 \\
20 \\
16 \\
24 \\
16 \\
12 \\
24 \\
19 \\
19 \\
16 \\
9\end{array}$ & $\begin{array}{l}c m . \\
0.2 \\
3.4 \\
2.2 \\
1.0 \\
3.0 \\
2.3 \\
2.2 \\
1.6 \\
1.7 \\
3.5 \\
2.9 \\
0.6 \\
0.4 \\
1.6 \\
2.7 \\
3.2 \\
2.3 \\
2.2 \\
3.1 \\
1.9 \\
2.2 \\
3.7 \\
3.5 \\
3.8 \\
2.6 \\
2.4\end{array}$ \\
\hline $\begin{array}{c}\text { Mean and } \\
\text { probable error }\end{array}$ & $73.4 \pm 1.20$ & $\begin{array}{c}3.6 \\
\pm \\
0.22\end{array}$ & $\begin{array}{c}4.4 \\
\pm \\
0.21\end{array}$ & $\begin{array}{l}4.0 \\
\pm \\
0.21\end{array}$ & $\begin{array}{c}16 \\
\pm \\
0.79\end{array}$ & $\begin{array}{c}2.4 \\
\pm \\
0.13\end{array}$ \\
\hline $\begin{array}{l}\text { Standard } \\
\text { deviation }\end{array}$ & 9.1 & 1.7 & 1.6 & 1.6 & 6.0 & 1.0 \\
\hline
\end{tabular}

* Measured from a doubly exposed roentgenogram: at maximum expiration and inspiration.

to expand the chest in pulmonary emphysema, which tends to be proportional to the degree of abnormality in the ratio of residual air to total capacity.

\section{DISCUSSION}

The term emphysema is one which is frequently used loosely. Various types of the disorder may be recognized. One form is the compensatory emphysema which develops in some portions of the lungs when other portions are rendered airless by any one of a variety of pathological proc- 
esses. "Physiological" emphysema is found in individuals at high altitudes. The two remaining types may be described as the obstructive and non-obstructive. The former occurs in association with bronchial obstruction by bronchitis or asthma. The latter is believed to be due to extra pulmonary causes. Kountz and Alexander (19) have studied the nonobstructive type which they believe is due primarily to an increase in the size of the chest resulting from a straightening of the dorsal spine. In this type there is probably little if any loss of respiratory function. We have investigated one such case, the findings of which are presented in Figure 6 for the purpose of comparison with the obstructive type. In this case there was no history of dyspnea or any other symptom referable to the respiratory system, the diagnosis of pulmonary emphysema was made on the suggestive appearance of the chest. Determination of the pulmonary capacity revealed a decreased vital capacity but a normal volume of residual air and a normal ratio of this volume to the total capacity. This case serves to emphasize the importance of differentiating the two types, one of which appears to be chiefly an anatomical abnormality in which respiratory function is slightly disturbed, the other a functional disturbance of great clinical significance. Determinations of pulmonary capacity are helpful in deciding to which group an individual case belongs.

From the clinical history of our patients it will readily be seen that they belong to the obstructive type of emphysema, with respiratory disability of varying degree. There was a history of chronic bronchial asthma or bronchitis in all cases. A comparison of this group as a whole with that of normal male subjects studied under similar conditions and with identical technique will be helpful in understanding the different factors which enter into the pathological physiology of pulmonary emphysema. Such comparison is made in Table VI and Figure 7. Patients with emphysema are characterized as a rule by an unusually voluminous chest, by a low position of the diaphragm. The chest in such cases tends to assume a rounded as well as an elongated shape, as though it were permanently in the position of deep inspiration. Such an abnormal chest moves less than that of a normal man and this diminution of expansion was demonstrated by the limited excursion of the diaphragms, by less than normal change in the lateral and antero-posterior diameters of the chest and by the decreased rotation of the ribs. These abnormalities in the mensuration of the thorax are strikingly reflected and paralleled by alterations in the capacities of the lungs. The amount of air which such a patient is able to take into his lungs by a forced inspiration is markedly reduced, and this is due, literally speaking, to the fact that these organs already contain an increased volume of air. In obstructive emphysema the mid capacity at the end of the usual expiration is higher than normal, with the result that each tidal inspiration must diffuse with a larger volume 

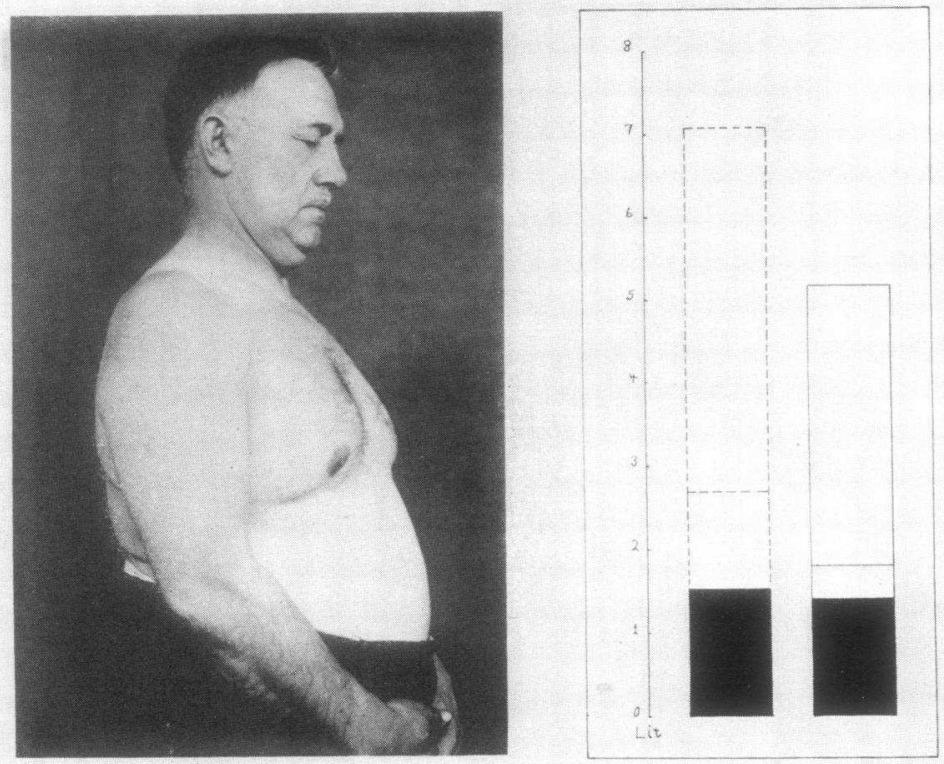

Fig. 6. Plimonary Capacity in a Case of Non-Opstrlctive Emphysema With No Respiratory Disability

Chest has a definite emphysematous appearance. The vital capacity is decreased but the absolute and relative values of the residual air are normal. ( Ratio $\frac{\text { Residual air }}{\text { Total capacity }} \times 100=27.5$ per cent.)

of air in order to ventilate the alveoli properly. It is apparent that this lack of physiological balance between the volume of air to be ventilated and air available for such ventilation, together with the decreased ability to properly expand the chest, assumes a much greater significance during physical activity when the heightened body metabolism demands an increase in alveolar ventilation.

We may now inquire into the anatomical and functional mechanisms responsible for the abnormalities found in patients with pulmonary emphysema. Although postmortem studies of emphysematous lungs do not always present a uniform picture there is general agreement that certain common findings constitute the anatomical background. When the thorax is opened the lungs appear voluminous and do not collapse. There is usually dilatation and an ischemic appearance of the alveoli chiefly in the peripheral zones. Histologically the alveoli are found to be large and in many places two or more are united in a single cavity due to broken walls. The alveolar walls are usually thinned, stretched, torn and atrophied and the capillaries obliterated. The respiratory bronchioles also present ab- 
HURTADO, KALTREIDER, FRAY, BROOKS AND MCCANN

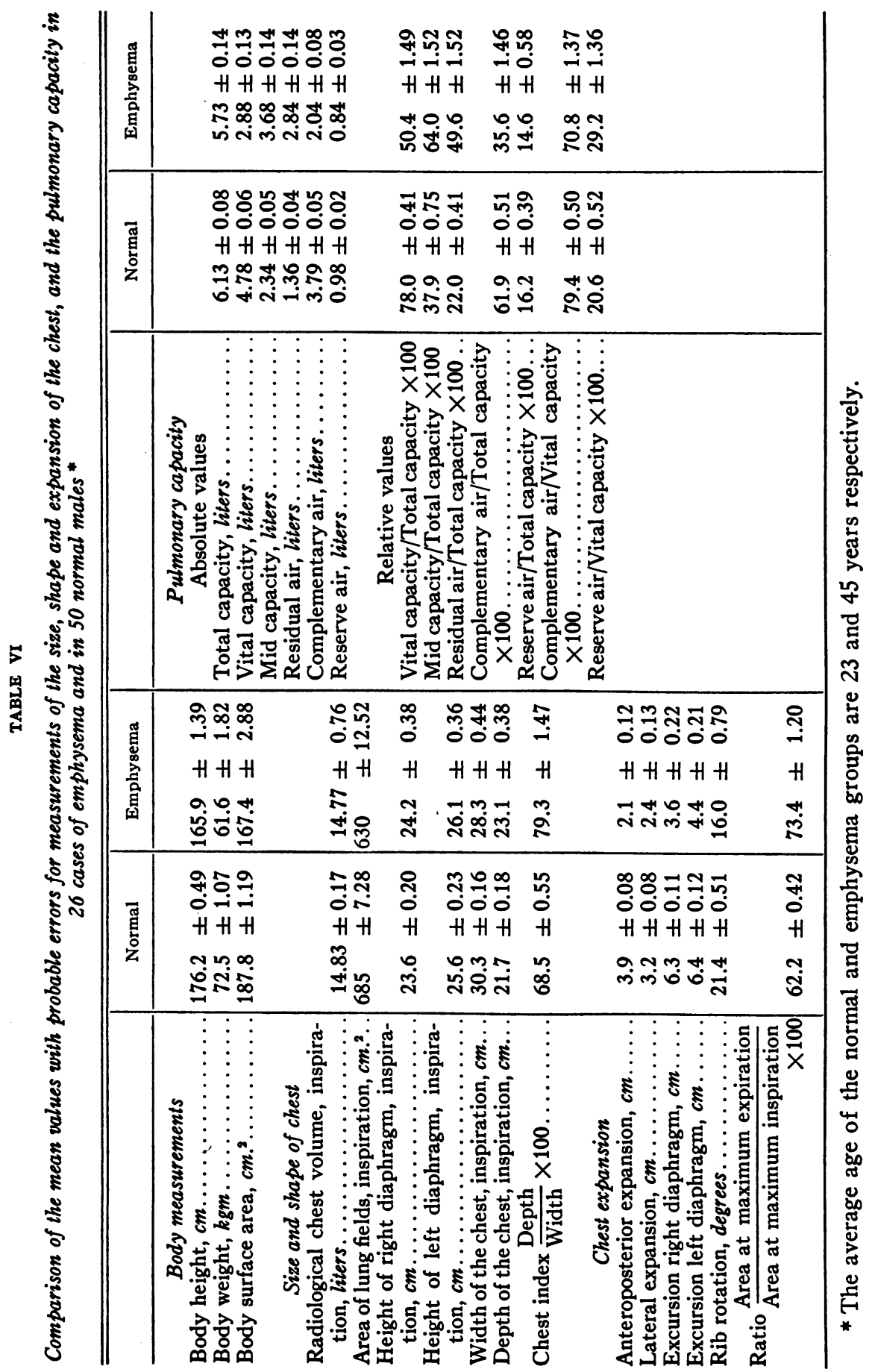



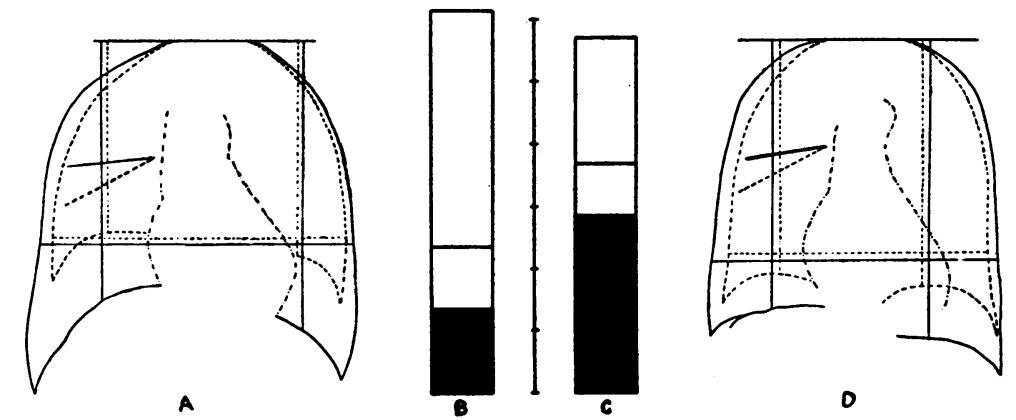

Fig. 7. Comparison of the Average Chest Size and Expansion and the Pulmonary Capacity in a Group of 26 Cases of Emphysema (Obstructive Type) with the Corresponding Average Measurements in a Group of 50 Normal Males. (For actual values see Table VI.)

$A$. Outline of the lung fields of normal subjects at the respiratory positions of forced expiration and inspiration.

$B$. Pulmonary capacity in normal subjects.

C. Pulmonary capacity in emphysema.

$D$. Outline of the lung fields at the respiratory positions of deep expiration and inspiration in emphysema.

normalities in their structure, showing dilatation or evidence of a chronic infective process.

The functional abnormalities of the emphysematous lungs have been discussed recently by Christie (18) in a most interesting and careful study. According to this investigator (to whom we refer the reader for a complete presentation of the related literature) the fundamental factor in the emphysematous lung is a loss of elasticity causing a gradual increase in the residual air, as the lungs yield to the continuously exerted negative pressure at the pleura. The intrapleural pressure increases, shifting to positive values, a fact which has been reported by other investigators (Kountz, Pearson and Koenig (20)). It is obvious from these observations that we are dealing in pulmonary emphysema with a fundamental abnormality in the mechanics of the respiratory process concerned with the proper alveolar ventilation, the importance of which has been admirably summarized by Peabody (21) in the following sentence: "Nevertheless, it remains true that the respiratory process is initiated in the rhythmic expansion and collapse of the lungs and all other phases of respiration depend primarily on the comparatively simple mechanical movements." When we consider the relationship of abnormal pulmonary capacities to the degree of respiratory disability we find in the literature that of all the subdivisions, the vital capacity is the one to which chiefly attention has been paid, especially in the fundamental and classical work of Peabody 
and his co-workers, which has been recently summarized by Burwell (22). It is of special importance, however, to know the ratio $\frac{\text { Residual air }}{\text { Total capacity }}$ pulmonary emphysema, in which the residual air is always increased. Our observations indicate that this ratio has great functional significance.

Some investigators have already pointed out the value of such determinations in pulmonary and cardiac diseases and in other conditions. Binger (23) in 1923 found a correlation between the ratio of the vital to the total capacity and the clinical condition of patients with heart disease. Bendove (24) in 1925 observed that in tuberculosis patients with a low vital capacity there was marked dyspnea, while in cases in which a therapeutic pneumothorax had been induced and where the same low vital capacity existed there was no appreciable dyspnea. This difference he attributed to the fact that the residual air had also been reduced so that a more efficient alveolar ventilation was possible. In 1930 Meakins and Christie (25) wrote: "the efficiency of the pulmonary ventilation would appear to rest upon the relationship between the residual air and the total lung capacity." Robb and Weiss (26) in 1932 reported that both in cardiac patients and in those with hyperthyroidism the ratio of residual air to the vital capacity was correlated with the degree of dyspnea present and that this ratio decreased as the condition of the patient improved. We have correlated in Table VII the degree of dyspnea, with the ratio of re-

TABLE VII

Relation of dyspnea to changes in the pulmonary capacity

\begin{tabular}{c|c|c|c|c}
\hline \hline Dyspnea* & $\begin{array}{c}\text { Number } \\
\text { of } \\
\text { cases }\end{array}$ & $\begin{array}{c}\text { Decrease in } \\
\text { vital capacity }\end{array}$ & $\begin{array}{c}\text { Increase in } \\
\text { residual air }\end{array}$ & $\begin{array}{c}\text { Residual air } \\
\text { Total capacity }\end{array} \times 100$ \\
\hline & & per cent & per cent & \\
+ & 7 & -18.3 & +72.0 & 38.3 \\
++ & 8 & 33.8 & 84.5 & 43.5 \\
+++ & 8 & 54.5 & 158.1 & 60.8 \\
++++ & 1 & 60.9 & 267.7 & 72.5 \\
\hline
\end{tabular}

* Degree of dyspnea indicated by + : dyspnea only on severe physical activity; ++ : on moderate exertion; +++ : on slight physical activity; and +++ : at rest.

sidual air to total capacity. ${ }^{3}$ The degree of dyspnea was estimated from the history and in a few cases from actual observations made during physical activity. A striking relationship between the degree of dyspnea and the value found for the ratio, $\frac{\text { Residual air }}{\text { Total capacity }} \times 100$ is shown in Figure 8.

${ }^{3}$ We have omitted Cases 14 and 26 in this comparative study on account of lack of precise information regarding the degree of dyspnea. 


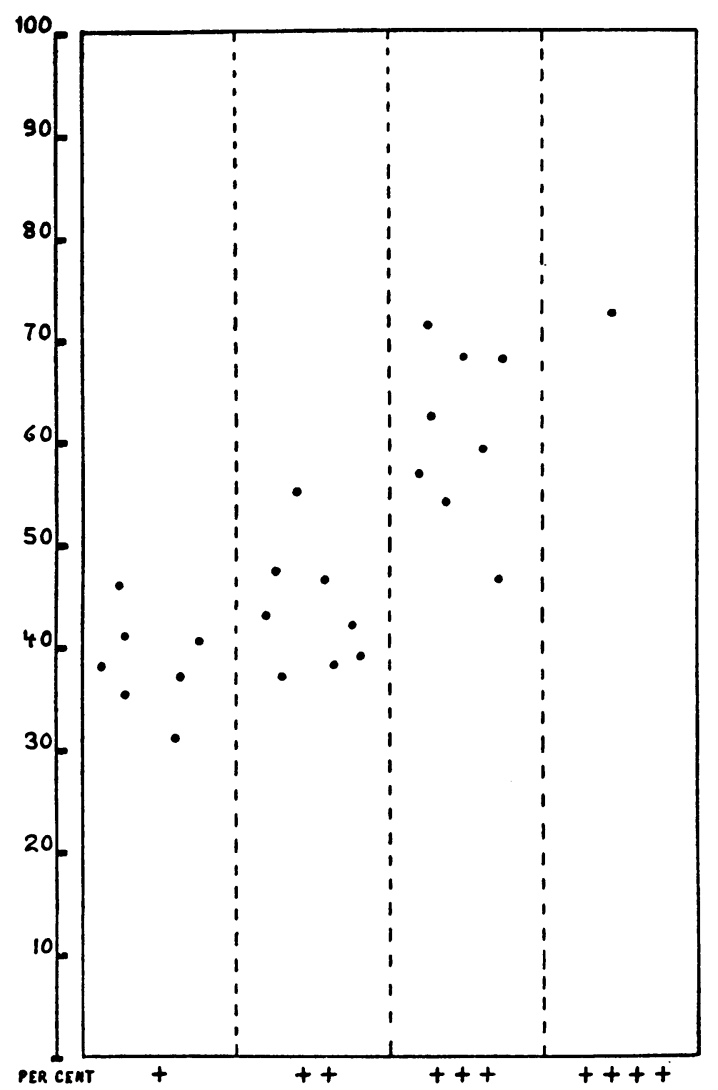

Fig. 8. Relation of Dyspnea to the Ratio $\frac{\text { Residual Air }}{\text { Total Capacity }} \times 100$ in Pulmonary Emphysema

$+\quad$ Dyspnea only on severe physical activity.

+ Dyspnea on moderate exertion.

++ Dyspnea on slight physical activity.

+++ Dyspnea at rest.

From such correlation it appears that the increase in this ratio is not only a constant feature of pulmonary emphysema but that its value is closely related to the degree of respiratory disability, furnishing a quantitative basis for the estimation of the latter.

The importance, from the diagnostic and prognostic points of view, of having such a quantitative estimation is obvious. Yates (27) in 1925 called attention to the fact that intrathoracic operations on patients suffering from emphysema are extraordinarily hazardous. We have personally observed two cases with a high ratio of residual air to total capacity, who were submitted to surgical procedures in the thorax; one of 
them died shortly after the operation and the other had a long and stormy convalescence. The accuracy of the diagnosis of pulmonary emphysema, as well as the proper estimation of the degree of respiratory disability would be of considerable help in such cases. In chronic bronchial asthma, also, the development of pulmonary emphysema and the estimation of the degree of respiratory disability is of importance. In this condition the determination of the ratio of residual air to total pulmonary capacity may have value. A comparison in such cases of the pulmonary capacity with the duration of the asthma is summarized in Table VIII. No definite

TABLE VIII

Correlation between duration of asthmatic history and pulmonary capacity

\begin{tabular}{c|c|c|c|c}
\hline \hline $\begin{array}{c}\text { Duration of } \\
\text { asthmatic } \\
\text { attacks }\end{array}$ & $\begin{array}{c}\text { Number } \\
\text { of } \\
\text { cases }\end{array}$ & $\begin{array}{c}\text { Decrease in } \\
\text { vital capacity }\end{array}$ & $\begin{array}{c}\text { Increase in } \\
\text { residual air }\end{array}$ & $\frac{\begin{array}{c}\text { Ratio } \\
\text { Residual air }\end{array}}{\text { Total capacity }} \times 100$ \\
\hline Less than 5 years. & 7 & per cent & per cent & \\
From 5-10 years... & 6 & 30.2 & 105.6 & 44.4 \\
From 10-20 years.. & 5 & 42.0 & 84.8 & 49.0 \\
Over 20 years.... & 5 & 34.1 & 92.4 & 46.8 \\
\hline
\end{tabular}

relationship was found between these factors, suggesting that there must be other factors apart from the chronicity of the asthma influencing the development of pulmonary emphysema in these patients.

Finally we wish to call attention to the absence of serious cardiac complications in this group of cases of pulmonary emphysema. This is in agreement with the investigations of Alexander, Luten and Kountz (28) and Kountz, Alexander and Dowell (29).

\section{SUMMARY AND CONCLUSIONS}

Determinations of total pulmonary capacity and its subdivisions and measurements of the capacity to expand the chest have been made in twenty-six cases of pulmonary emphysema of the obstructive type. The findings have been correlated with the degree of respiratory disability, and lead to the following conclusions :

1. The ability to expand the chest in pulmonary emphysema is diminished.

2. There are definite alterations in the subdivisions of the pulmonary capacity consisting chiefly in absolute and relative decrease in the vital capacity, and absolute and relative increase of the mid capacity and residual air. The total capacity is as a rule normal.

3. The decrease in the vital capacity affects chiefly the complementary air. Decrease or disappearance of the reserve air after a deep inspiration is not a constant finding in all cases of pulmonary emphysema. 
4. Although no definite conclusion has been reached as to the value for the respiratory dead space in pulmonary emphysema it appears likely that no significant alteration from normal is present.

5. The degree of respiratory disability has been found to be closely correlated with the ratio, $\frac{\text { Residual air }}{\text { Total capacity }} \times 100$. The higher this ratio the more pronounced is the failure of respiratory adaptation to physical activity.

6. The significance of this ratio as an indication of the efficiency of the alveolar ventilation, and its usefulness in pulmonary emphysema for diagnostic and prognostic purposes has been discussed.

\section{BIBLIOGRAPHY}

1. Hurtado, A., and Boller, C., Studies of total pulmonary capacity and its subdivisions. I. Normal, absolute and relative values. J. Clin. Invest., 1933, 12, 793.

2. Hurtado, A., and Fray, W. W., Studies of total pulmonary capacity and its subdivisions. II. Correlation with physical and radiological measurements. J. Clin. Invest., 1933, 12, 807.

3. Christie, R. V., The lung volume and its subdivisions. I. Methods of measurements. J. Clin. Invest., 1932, 11, 1099.

4. Hurtado, A., Fray, W. W., Kaltreider, N. L., and Brooks, W. D. W., Studies of total pulmonary capacity and its subdivisions. V. Normal values in female subjects. J. Clin. Invest., 1934, 13, 169.

5. Eyster, J. A. E., The clinical aspects of venous pressure. Macmillan Co., New York, 1929.

6. Bowen, B. D., The relation of age and obesity to vital capacity. Arch. Int. Med., 1923, 31, 579.

7. Myers, J. A., and Cady, L. H., Studies on the respiratory organs in health and disease. XIII. The effects of senility on the vital capacity of the lungs. Am. Rev. Tuberc., 1924, 9, 57.

8. Lemon, W. S., and Moersch, H. J., Factors influencing vital capacity Arch. Int. Med., 1924, 33, 136.

9. Pratt, J. H., Long continued observations on the vital capacity in health and heart disease. Am. J. M. Sc., 1922, 164, 819.

10. Bruns, O., Die Bedentung der spirometrischen Untersuchung von Emphysematikern und Herzkranken. Med. Klin., 1910, 6, 1524.

11. Bittorf, A., and Forschbach, J., Untersuchung über die Lungenfüllung bei Krankheiten. Ztschr. f. klin. Med., 1910, 70, 474.

12. Porges, O., Leimdörfer, A., and Markovici, E., Ueber die Kohlensäurespannung des Blutes in pathologischen Zuständen. II. Ueber die Kohlensäurespannung des Blutes in der kardialen und pulmonalen Dyspnoe. Ztschr. f. klin. Med., 1913, 77, 446.

13. Plesch, J., Die pathologische Physiologie des Lungenvolumens und seine Beziehung zum Kreislauf. Ztschr. f. exper. Path. u. Therap., 1913, 13, 165.

14. Lundsgaard, C., and Schierbeck, K., Studies on lung volume. IX. Patients with lung emphysema pulmonum. Proc. Soc. Exper. Biol. and Med., 1922-23, 20, 165.

15. Anthony, A. J., Untersuchungen über Lungenvolumina und Lungenventilation. Deutsches Arch. f. klin. Med., 1930, 167, 129. 
16. Herms, J., and Rüttgers, I., Lungenvolumina, ventilation und Arbeitstoffwechsel beim Lungenemphysem. Beitr. z. klin. Tuberk., 1931, 78, 724.

17. Hurtado, A., Fray, W. W., and McCann, Wm. S., Studies of total pulmonary capacity and its subdivisions. IV. Preliminary observations on cases of pulmonary emphysema and of pneumoconiosis. J. Clin. Invest., 1933, 12, 833.

18. Christie, R. V., The elastic properties of the emphysematous lung and their clinical significance. J. Clin. Invest., 1934, 13, 295.

19. Kountz, W. B., and Alexander, H. L., Non-obstructive emphysema. J. A. M. A., 1933, 100, 551 .

20. Kountz, W. B., Pearson, E. F., and Koenig, K. F., Observations on intrapleural pressure and its influence on the relative circulation rate in emphysema. J. Clin. Invest., 1932, 11, 1281.

21. Peabody, F. W., The aspects of the respiration referable to the lungs. $\operatorname{Tr}$. A. Am. Physicians, 1924, 39, 52.

22. Burwell, C. S., A practical consideration of the pathological physiology of the circulation. Dyspnea as a symptom of disease. Internat. Clin., 1933, $2,43$.

23. Binger, C. A. L., The lung volume in heart disease. J. Exper. Med., 1923, $38,445$.

24. Bendove, R. A., The vital capacity in artificial pneumothorax. Arch. Int. Med., 1925, 36, 94.

25. Meakins, J. C., and Christie, R. V., Lung volume and its variations. Ann. Int. Med., 1929-30, 3, 423.

26. Robb, G. P., and Weiss, S., The rôle of the pulmonary circulation in the dyspnea of circulatory failure and of hyperthyroidism. J. Clin. Invest., Proc., 1932, 11, 823.

27. Yates, J. L., The significance of vital capacity in intrathoracic surgery. Arch. Surg., 1925, 10, 477.

28. Alexander, H. L., Luten, D., and Kountz, W. B., Effects on the heart of long standing bronchial asthma. J. A. M. A., 1927, 88, 882.

29. Kountz, W. B., Alexander, H. L., and Dowell, D., Emphysema simulating cardiac decompensation. J. A. M. A., 1929, 93, 1369.

\section{APPENDIX}

Case 1. Male, 61 years. No history of asthmatic attacks. Dyspnea $(+++)$ and cough for 3 years. Marked cyanosis and clubbing of the fingers. Chest emphysematous in appearance with hyperresonant percussion note and a few scattered râles. Electrocardiogram showed myocardial damage and intraventricular conduction defect. Roentgenograph: lung markings greatly exaggerated with marked emphysematous changes. Left ventricular hypertrophy.

Case 2. Male, 48 years. Mild asthmatic attacks, dyspnea $(++)$ and cough for 3 years. Chest not emphysematous. Expiration prolonged. Electrocardiogram showed left ventricular preponderance. Roentgenograph : slight increase in linear markings especially in hilar regions. Flaring of the ribs.

Case 3. Male, 55 years. Asthmatic attacks, dyspnea $(+++)$ and cough for 20 years. Chest markedly emphysematous with hyperresonant percussion note, prolonged expiration with scattered musical râles. Marked cyanosis. Electrocardiogram normal. Roentgenograph: increased linear markings.

\footnotetext{
+ dyspnea only on severe physical activity.

++ dyspnea on moderate exertion.

++ dyspnea on slight physical activity.

++++ dyspnea at rest.
} 
Case 4. Male, 60 years. No history of asthmatic attacks. Dyspnea $(+)$ and mild cough for 1 year. Emphysematous chest with prolonged expiration. Electrocardiogram presented evidence of myocardial damage. Roentgenograph : increased linear markings, flaring of the ribs.

Case 5. Male, 60 years. Asthmatic attacks for 19 years. Dyspnea $(++)$ and severe cough for 10 years. Chest not emphysematous; hyperresonant percussion note and numerous musical râles. Roentgenograph: marked increase in linear markings, especially at the hilar regions.

Case 6. Male, 63 years. Asthmatic attacks, dyspnea $(++)$ and cough for 40 years. Marked cyanosis and slight clubbing of the fingers. Emphysematous chest with marked hyperresonant percussion note and prolonged expiration; scattered musical râles. Electrocardiogram showed left ventricular preponderance. Roentgenograph: exaggerated linear markings, emphysematous bases.

Case 7. Male, 26 years. Attacks of asthma for 20 years. Dyspnea $(+)$ for 1 year. Negative chest examination. Roentgenograph: increased linear markings and increase in the size of the hilar shadows.

Case 8. Male, 43 years. Asthmatic attacks, dyspnea ( ++$)$ and cough for 6 years. Chest markedly emphysematous; dorsal kyphosis. Hyperresonant percussion note and prolongation of the expiration. Electrocardiogram normal. Roentgenograph: dense shadow at the right apex. Increased markings.

Case 9. Male, 64 years. Asthmatic attacks, dyspnea $(+++)$ and cough for 30 years. Chest not emphysematous. Percussion note hyperresonant; prolongation of breath sounds with numerous râles. Electrocardiogram showed evidence of myocardial damage. Roentgenograph: increased linear markings, low flat diaphragm, pleural thickening about diaphragm.

Case 10. Male, 52 years. Asthmatic attacks, cough and dyspnea $(++)$ for four and a half years. Chest not emphysematous; percussion note hyperresonant and expiration prolonged. Roentgenograph: increased linear markings and radiability of lung fields, flaring of the ribs, wide intercostal spaces.

Case 11. Male, 52 years. Asthmatic attacks, dyspnea $(++)$ and cough for 5 years. Chest not emphysematous; hyperresonant percussion note, expiration prolonged accompanied by a few scattered musical râles. Roentgenograph : increased linear markings, especially at the hilar zones, increased radiability of the lung fields and flaring of the ribs.

Case 12. Male, 45 years. Asthmatic attacks, dyspnea $(+++)$ and cough for 6 years. Emphysematous chest; hyperresonant percussion note, distant breath sounds with râles and rhonchi. Electrocardiogram showed left ventricular preponderance and sinus tachycardia. Roentgenograph: increased radiability of lung fields, flat diaphragms. Old fibrosis and calcification at right apex.

Case 13. Male, 52 years. Asthmatic attacks, dyspnea $(++++)$ and severe cough for probably 1 year. Emphysematous chest; expiration prolonged scattered musical râles. Electrocardiogram showed evidence of myocardial damage. Roentgenograph: prominent linear markings, increase in size and density of hilar shadows. After lipiodol injection a questionable diagnosis of bronchiectasis.

Case 14. Female, 36 years. Asthmatic attacks for 35 years. Dyspnea probably for several years. Emphysematous chest, with hyperresonant percussion note. Electrocardiogram showed sino-auricular tachycardia. Roentgenograph: prominent linear markings with increase in density of hilar shadows; fine feathering over right lung and shadows of increased density in left lung.

Case 15. Male, 32 years. Asthmatic attacks, dyspnea $(+)$ and cough for 
12 years. Chest not emphysematous, percussion note hyperresonant, expiration prolonged. Roentgenograph: increased radiability at the lung bases with flaring of the ribs.

Case 16. Male, 41 years. Attacks of asthma, dyspnea $(+)$ and cough for 10 years. Slight clubbing of the fingers. Thorax: hyperresonant percussion note and prolongation of the expiration with few scattered râles. Roentgenograph: increased linear markings, increased radiability of lung fields, flaring of ribs.

Case 17. Male, 41 years. Asthmatic attacks for 10 years. Dyspnea $(+++)$ and severe cough for 26 years. Slight cyanosis of mucous membranes. Emphysematous chest; percussion note hyperresonant, prolongation of breath sounds with numerous musical râles. Electrocardiogram normal. Roentgenograph: increased linear markings especially in both lower fields and in hilar shadows, low flat diaphragm.

Case 18. Male, 38 years. Asthmatic attacks, dyspnea $(++)$ and cough for probably 4 years. Slight cyanosis; marked clubbing of the fingers. Chest not emphysematous; percussion note resonant, prolonged expiration, scattered musical râles. Electrocardiogram showed left ventricular preponderance. Roentgenograph : increased linear markings and enlarged hilar shadows. Dorsal scoliosis.

Case 19. Female, 28 years. Asthmatic attacks, dyspnea $(+)$ and cough for 7 years. Chest normal. Roentgenograph: increased linear markings, especially at the hilar regions.

Case 20. Male, 43 years. Asthmatic attacks, dyspnea $(+++)$ and cough for probably 30 years. Emphysematous chest; prolonged expiration and scattered râles. Electrocardiogram presented left ventricular preponderance. Roentgenograph: increased linear markings, enlarged hilar shadows, low diaphragm, bulging of the ribs. Prominent pulmonary conus.

Case 21. Male, 50 years. Asthmatic attacks, dyspnea $(+++)$ and severe cough for 6 years. Emphysematous chest; hyperresonant percussion note, expiration prolonged. Electrocardiogram normal. Roentgenograph: increased linear markings and enlarged hilar shadows.

Case 22. Male, 17 years. Asthmatic attacks, dyspnea $(+)$ and cough for 1 year. Chest examination negative. Roentgenograph : increased linear markings, more marked at both bases; enlarged hilar shadows.

Case 23. Male, 49 years. Asthmatic attacks, dyspnea $(++)$ and cough for 2 years. Slight cyanosis. Chest not emphysematous, prolonged expiration and scattered musical râles. Electrocardiogram showed left ventricular preponderance. Roentgenograph: increased linear markings with enlarged hilar shadows. Sclerosis of the aorta.

Case 24. Male, 17 years. Asthmatic attack, dyspnea (+) and severe cough for 1 year. Chest normal. Roentgenograph: increased linear markings, especially at the hilar regions.

Case 25. Male, 43 years. Asthmatic attacks, dyspnea $(++)$ and cough for 5 years. Emphysematous chest; prolonged expiration and scattered musical and coarse râles. Roentgenograph: prominent linear markings with increased radiability at both bases. Pleural thickening.

Case 26. Male, 55 years. No history of asthma. Dyspnea doubtful and cough. Slight cyanosis. Emphysematous chest; hyperresonant percussion note and scattered rhonchi. Electrocardiogram normal. Roentgenograph: slight increase in linear markings with feathering in both lower lung fields; increased radiability of lung fields; calcification of right pleura. 